Revista Tribuna Internacional

Volumen $8 \cdot \mathrm{N}^{\mathrm{o}} 15 \cdot 2019$

ISSN 0719-482X (versión en línea)

\title{
Hacia una escuela chilena de pensamiento político-jurídico antártico $^{1}$
}

\section{Towards a Chilean school of political and legal Antarctic thinking}

\author{
Luis Valentín Ferrada Walker \\ lvferrada@derecho.uchile.cl \\ Doctor en Derecho. Profesor de Derecho Internacional Público, Universidad de Chile.
}

Ese enorme continente por siglos escondido en el extremo sur del planeta, y al que los antiguos cartógrafos bautizaron con el sugerente nombre de Terra Australis Incognita, se vinculó desde siempre y profundamente con nuestro país. Así lo consignó Alonso de Ercilla en La Araucana, poema épico que constituye la partida de nacimiento de Chile. Es un espacio mítico sobre el que se reflexiona ya desde la época de los griegos, y que es puesto bajo la autoridad de los Gobernadores de Chile desde la capitulación a Pedro Sancho de la Hoz en 1539, cedida luego en favor de Pedro de Valdivia. Como tal, es un continente que requiere ser buscado, descubierto. A comienzos del siglo XVII, navegando hacia el sur por las costas de Chile, Gabriel de Castilla habría sido el primero en llegar hasta la Antártica, descubriéndola por casualidad, mientras Pedro Fernández de Quirós la buscaba conscientemente navegando hacia el sur-poniente, aunque sin fortuna. Habrá de esperarse hasta 1820 para que bajo el impulso de la casa de focas la Antártica se incorporara propiamente al devenir mundial, y hasta el Tratado Antártico de 1959 para que alcanzara el estatus con el que hoy se la considera.

Según lo definiera el Profesor Jorge Millas (2012: 34), exalumno y profesor de nuestra Escuela, y uno de los grandes filósofos chilenos, una universidad es, en esencia, "una comunidad de maestros y discípulos destinada a la transmisión y el progreso del saber superior". Por lo mismo, el que exista, no un tópico, iiisi no que un continente entero!!! profundamente vinculado a nosotros y cuya esencia es el ser objeto de estudio, no puede sino que ser motivo de un gran regocijo.

Desde hace muchos años que nuestra Universidad y nuestra Facultad de Derecho han estado dedicadas al estudio de lo antártico y a la determinación de cuál es su relación con el Estado de

1 Palabras pronunciadas en el acto inaugural de las Jornadas Chilenas de Derecho Antártico 2019, Facultad de Derecho, Universidad de Chile, 28 de marzo del 2019. 
Chile. Un número significativo de quienes han intervenido desde la academia o la política en tales materias, han paseado en su momento por estos patios. Al hacer un listado siempre se corre el riesgo de olvidar a alguien, pero una nómina preliminar debiera al menos incluir a los Presidentes de la República Germán Riesco Errázuriz, Pedro Aguirre Cerda y Gabriel González Videla, y a personas que se han tenido un destacado desempeñado en el ámbito de las relaciones exteriores o del derecho internacional tal como Antonio Huneeus Gana, Marcial Mora Miranda, Julio Escudero Guzmán, Oscar Pinochet de la Barra, Francisco Orrego Vicuña, María Teresa Infante Caffi o María Luisa Carvallo Cruz. Todos ellos han sido alumnos y/o profesores de esta Facultad.

Sin embargo, para una Universidad no basta con tener un conjunto de personas que hayan hecho aportes individuales, por importantes que estos sean. Le es necesario ir un poco más allá, le es necesario hacer escuela y, como se ha expresado en un contexto equivalente, "una 'escuela del pensamiento' es más que un mero punto de encuentro. Ella implica una comunidad de académicos que se identifican como tal, comparten ideas sobre el proceso social, un mismo sentido de misión respecto a dicho proceso y una metodología común" (Reisman, Wiessner y Willard, 2012: 12). Esto es lo que nos faltaba hasta ahora. A esto es a lo que estamos hoy abocados. Y estas Jornadas Chilenas de Derecho Antártico que inauguramos no tienen más pretensión que ser un hito en tal proceso.

Tendremos el honor de escuchar durante esta mañana a un grupo de invitados realmente de lujo. Es el caso del diplomático multilateralista Camilo Sanhueza Bezanilla, Director de Antártica de nuestra Cancillería y el funcionario público de más alto rango dentro del Estado de Chile con competencia exclusiva sobre temas antárticos. Recibiremos también a la profesora Julia Jabour, de la Universidad de Tasmania, la mayor especialista en temas jurídico antárticos de su país en las últimas décadas, y quien desde el Ocean \& Antarctic Governance Research Program del Institute for Marine \& Antarctic Studies (IMAS) ha impulsado con gran éxito su estudio desde perspectivas multi e interdisciplinaria, enriqueciendo la comprensión del derecho. Lo mismo debemos decir del profesor Akiho Shibata, de la Universidad de Kobe, en Japón, Director del Polar Cooperation Research Centre, y quien ha tenido la responsabilidad de participar en nombre de su país en las negociaciones de importantes instrumentos jurídicos antárticos. Finalmente, el profesor Gustavo Ramírez, académico de la Universidad de Magallanes y que cursa actualmente estudios doctorales en la Philipps-Universität Marburg, Alemania, es parte fundamental de las nuevas generaciones de juristas chilenos que tendrán la responsabilidad esencial de orientar desde la academia el desarrollo de la política antártica nacional durante las próximas décadas.

Junto a ellos, en la jornada de la tarde, tendremos la oportunidad de escuchar a un grupo de jóvenes investigadores que, como profesor de esta Escuela, me llenan de la mayor satisfacción y orgullo. Este conjunto de abogados, egresados o alumnos ya próximos a egresar, han sido algunos de los tesistas con quienes durante los últimos años hemos investigado, reflexionado y debatido respecto a los desafíos político-jurídicos que plantean la Antártica para el derecho 
Revista Tribuna Internacional

Volumen $8 \cdot \mathrm{N}^{\circ} 15 \cdot 2019$

ISSN 0719-482X (versión en línea)

internacional. Han hecho contribuciones importantes, significativas, que estoy seguro servirán para sustentar esta escuela de pensamiento jurídico antártico que estamos empeñados en impulsar. Las tres primeras intervenciones abordarán aspectos del Sistema del Tratado Antártico. Gisselle Gajardo Flores, se referirá a las discusiones respecto al estatus jurídico del sexto continente; Chantal Lazen Muñoz, reflexionará sobre la aplicación de la regla del consenso como mecanismo para adoptar acuerdos en las Reuniones Consultivas del Tratado Antártico; y Giovannina Sutherland Condorelli, explicará por qué no resulta posible utilizar la categoría de Patrimonio Común de la Humanidad para la Antártica. El segundo bloque se enfocará en la explotación de los recursos antárticos y los desafíos que ello plantea. Carolina Flores Barros, ayudante del Departamento de Derecho Internacional y a quien debemos desde ya agradecer todo su trabajo para que estar jornadas se materializaran, se referirá a la regulación chilena para las actividades turísticas; Cristián Arroyo Cortés abordará luego los conflictos que plantea la regulación o desregulación de las actividades de bioprospección; y finalmente, Catalina Sepúlveda Illanes analizará las controversias y desafíos que platea la patentabilidad de los biorrecursos antárticos.

Estos seis jóvenes investigadores representan a un grupo mucho mayor de alumnos de nuestra Escuela que han estado interesados en profundizar en estas materias. Enmarcado en un proyecto Fondecyt del que soy investigador responsable, y al que debemos agradecer también que esta reunión sea posible, se ha realizado los últimos años el taller de tesis "Antártica. Problemas actuales y perspectivas político-jurídicas”. El año 2017 concluyó con un total de siete alumnos de pregrado más un alumno de magister que hicieron sus tesis sobre diversas temáticas relacionadas; el año 2018 aumentaron a ocho alumnos chilenos más dos alumnos de intercambio; y este año 2019 el taller reúne a 25 alumnos, incluyendo dos alumnos de intercambio. Como docente, es un tremendo desafío el ser capaz de satisfacer las expectativas de estos jóvenes, pero tal vez sea mayor la tarea para ellos, que deben ser capaces de buscar soluciones para los complejos e interesantísimos problemas que la Antártica plantea hoy al sistema internacional y a cada uno de los Estados que participan en sus regímenes.

Dentro de las complejidades que impone la Antártica a un mundo académico muchas veces excesivamente especializado y compartimentado, está la imprescindible necesidad de una perspectiva multi e interdisciplinaria. Por ello, este es un trabajo que no se puede hacer en solitario, iiiel Derecho Antártico es algo demasiado serio para dejárselo solo a los abogados!!! Quisiera agradecer, en este sentido, el permanente apoyo que de distintas formas hemos recibido de la Dirección de Antártica del Ministerio de Relaciones Exteriores, del Instituto Chileno Antártico y de las reparticiones en instituciones dependientes del Ministerio de Defensa Nacional. Pero además, y muy especialmente, quisiera agradecer a los profesores de la Universidad de Chile Francisco Hervé Allamand, de la Facultad de Ciencias Físicas y Matemáticas, y Elie Poulin, de la Facultad de Ciencias, quienes no solo son hoy dos de los más destacados científicos antártico a nivel mundial, sino que han impulsado permanentemente para 
que la Universidad tenga un programa antártico potente e incidente en las discusiones nacionales e internacionales. Agradecer asimismo a la Vicerrectoría de Investigación y Desarrollo, y muy especialmente a su Directora de Investigación, la profesora Silvia Nuñez, que hoy nos acompaña, que comprendiendo y haciendo suya tal preocupación está empeñada en potenciar este trabajo más allá de lo que una sola facultad o un grupo medianamente desarticulado de profesores e investigadores podríamos hacer.

Finalmente, ni estas jornadas ni nada de lo hecho durante los últimos años habría sido posible sin contar con el apoyo decidido y entusiasta de nuestra Facultad de Derecho y sus autoridades. Debo por lo mismo agradecer en lo personal al Decano, profesor Pablo Ruiz-Tagle Vial, al Director del Departamento de Derecho Internacional, profesor Claudio Troncoso Repetto, a la Directora de Relaciones Internacionales de la Facultad, profesora Ana María Moure Pino, y en su nombre a las demás autoridades, profesores y funcionarios de nuestra Escuela por el impulso y apoyo permanente que han dado a esta línea de investigación sobre Antártica.

Agradeciendo la presencia e interés de cada uno de los presentes en este auditorio, y el trabajo de todos quienes han hecho posible que esta iniciativa se concretara, los invito a reflexionar junto a nosotros, a escuchar, a preguntar, a comentar, a opinar, sobre un tema que, contra el sentir general, no es ni frío ni es lejano, sino que representa uno de los grandes desafíos actuales para la ciencia, para el derecho y para la política internacional: la Antártica. Los invitamos, en definitiva, a ser parte de esta escuela chilena de pensamiento jurídico-político antártico que estamos empeñados en desarrollar.

\section{Referencias bibliográficas}

Millas, Jorge (2012). Idea y defensa de la Universidad. Santiago, Ediciones UDP.

Reisman, W. Michael, Siegfried Wiessner y Andrew R. Willard (2012), “La New Haven School: Una breve introducción”. Revista Tribuna Internacional, 5(9): 11-18. doi:10.5354/0719482X.2016.41956. 